humus is supposed to act. Part of it forms insoluble salts with calcium and is precipitated with alcohol.

If a soil be boiled with an excess of calcium or barium salts and the soil afterwards extracted with ammonia the filtrate will usually have a color closely matching that of dilute ferric chloride. If the same soil is then leached with hydrochloric acid and again leached with ammonia, the resulting solution will have a much darker color which is often almost black. Yet barium or calcium salts precipitate the organic matter in the caustic potash soil extract, leaving an almost colorless supernatant liquid. The precipitation is not quantitative.

Further experiments are already under way in the laboratory and we hope to have further data of interest in regard to humus and soil analyses in connection with field experiments with fertilizers.

Chemical laboratory of N. OALANd \& Co.,

April 2, 19e0.

\title{
LECTURE EXPERIMENTS. REVERSIBLE CHEMICAL REACTIONS.
}

By W. LASH MILLER AND F, B, KENRICK. Received April II, 1900.

I ECTURES on physical chemistry are, at present, less in need $\mathcal{L}$ of experimental illustration than those on any other branch of the science, being delivered, for the most part, to small classes of advanced students, who have ample opportunity for experimenting in the laboratory. Some of the conceptions and discoveries which form the subject-matter of that department have, however, proved of such importance, that it is very desirable to incorporate them into the elementary course. This has hitherto been rendered difficult by the lack of suitable lecture experiments.

Among the most important of these discoveries, is that of the incompleteness and reversibility of a very large number of chemical reactions. The application of thermodynamical methods in the treatment of such cases is an achievement of the present day, and necessarily forms one of the chief subjects of study of advanced classes. The "average student," however, whose practical acquaintance with chemistry is limited to a course in 
analysis, knows nothing of all this. He knows the chenical reaction as a quantitative, non-reversible, and practically instantaneous phenomenon.

It does not occur to him that the reactions he meets with in the laboratory have all been selected because of these very properties, which render them convenient for the purposes of the analyst; generalizing from his one-sided experience, he is apt, half unconsciously, to form views on chemical affinity practically identical with those of Bergmann. Theories based on the rate of inversion of cane-sugar, and on Berthelot's experiments with alcohol and acetic acid-the experiments themselves are, unfortunately, quite unsuited to the lecture table-do not make much impression on one whose daily experience points in the other direction; if anything, they serve only to accentuate the feeling of unreality associated with the "other world" of organic chemistry.

Reactions involving the addition and removal of water of crystallization, or the formation and decomposition of double salts or other " molecular" compounds are likewise unsatisfactory. To be convinced, the student must see a "genuine" chemical reaction, $i . e$, one used in analysis or on the large scale in chemical manufacture, reversed before his eyes.

The following half dozen reactions have been selected from this point of view; the instructions include all the details that we have found necessary in exhibiting them before a large audience.

I. AMMONILM THIOCYANATE AND FERRIC CHLORIDE.

Approximately equivalent solutions of these substances are prepared, the first containing:

Ammonium thiocyanate.................. 7.5 grams

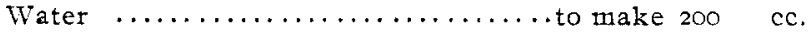

and the second :

Commercial (basic) ferric chloride ........... 6 grams

Concentrated hydrochloric acid (sp. gr. I.I75) ... 25 cc.

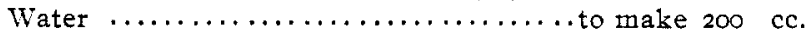

Five cc. of each are mixed in a large beaker, about two liters of (tap) water added, and the orange-colored mixture poured in equal quantities into four beakers. 
first $5 \mathrm{cc}$. am. thiocyanate solution. second $5 \mathrm{cc}$. ferric chloride solution. third $5 \circ \mathrm{cc}$. saturated am. chlor. sol. While the fourth is kept for comparison.

dark red
dark red
$\begin{gathered}\text { almost colorless } \\ \text { orange }\end{gathered}$

If the reaction be represented by the equation

$$
\mathrm{FeCl}_{3}+3 \mathrm{NH}_{4} \mathrm{SCN} \rightleftarrows \mathrm{Fe}(\mathrm{SCN})_{3}+3 \mathrm{NH}_{4} \mathrm{Cl}
$$

and the amount of ferric thiocyanate be judged from the depth of color of the solution, the reaction between equivalent quantities must be regarded as incomplete. The changes of color are interpreted by the arrows in the last column (indicating the direction of the reaction).

In order to show the effect of dilution in destroying the ferric thiocyanate (dissociation), equal quantities of the orangecolored mixture may be placed in two rectangular glass troughs of equal width, one of which is about twice as thick (from back to front) as the other. Water is then added to the solution in the larger trough until the level is the same in both, and a piece of white paper held at a little distance behind the two troughs. Seen from the front, the more dilute solution appears much less deeply colored than the other. For purposes of comparison, indigo or potassium permanganate may be used, which give the same color in the two vessels. Rectangular battery jars answer very well, as the change in color is so marked that unevenness in the glass is of no moment.

\section{BISMUTH CHLORIDE AND WATER.}

A "bismuth solution" is prepared as follows :

Commercial "bismuth trisnit" ............. 40 grans

Hydrochloric acid (sp. gr. I.I75) $\ldots \ldots \ldots \ldots \ldots, 40$ cc.

Rub together in a mortar, as the powder cakes; a trifling residue may be filtered off.

The reaction with water is represented by the equation:

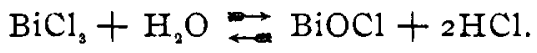

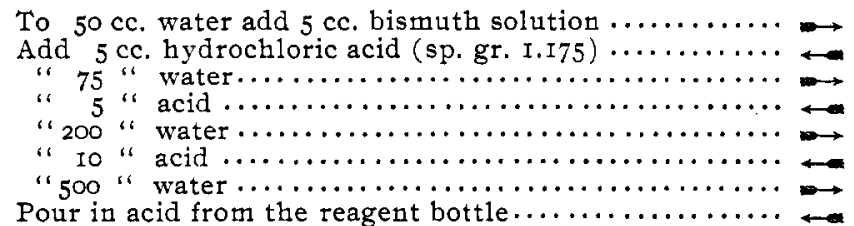


The reaction may be carried out in a glass cylinder, about three inches in diameter, holding about a liter. If small marks be made at the proper heights on the cylinder the water may be poured in without measuring.

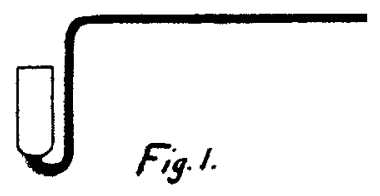

The acid may be delivered from a pipette or burette, or it may be dipped out of a beaker with the little measure figured in the margin (made of a piece of test-tube and a glass rod).

III. AMMONIA WITH SALTS OF COPPER AND OF SILVER.

Silver Bromide.-Excess of potassium bromide is added to I5 cc. of fifth-normal silver nitrate solution; the precipitate is washed once by decantation, shaken with $5 \mathrm{cc}$. of ammonia (sp. gr.0.915) and filtered. In the solution so obtained a precipitate is produced,

(a) adding a drop of potassium bromide solution,

(b) adding a drop of silver nitrate solution,

(c) adding five times its volume of water,

(d) boiling, or

(e) exposing (in a fractionating flask) to the vacuum of a filter-pump.

Copper Sulphate-Five cc. copper sulphate solution (IOo grams blue vitriol in I liter) are mixed with $5 \mathrm{cc}$. $5 / \mathrm{I}$ normal ammonia and diluted with $400 \mathrm{cc}$, distilled water. The addition of $400 \mathrm{cc}$. more distilled water produces a precipitate. If the reaction be carried out in a flat glass cell (an inch thick) with an incandescent lamp behind it, the change from clear to turbid is very distinct. This experiment should be rehearsed immediately before the lecture, as the presence of traces of acid, carbon dioxide, or ammonia salts, largely increases the amount of water necessary to produce a precipitate. If tap water be used instead of distilled water, half as much again may be required.

IV. FORMATION AND DISSOCIATION OF WATER, ETC.

Eudiometer. - A very convenient lecture table eudiometer con- 
sists of a straight glass tube ( $10 \mathrm{~mm}$. diameter and $760 \mathrm{~mm}$. long) open at one end and fused to a capillary with capillary tap at the other. The platinum wires are sealed through the wide tube just below its junction with the capillary, and the divisions are marked with rings of Brunswick black. A piece of iron pipe, widened at the mouth, serves as a mercury trough.

Measured volumes of the various gases $\left(\mathrm{H}_{2}, \mathrm{O}_{2}\right.$, $\mathrm{CO}, \mathrm{Cl}_{2}$, etc. ) may be admitted through the tap, if the endiometer be first filled with mercury, and the division corresponding to the volume desired be set level with the surface of the mercury in the iron tube.

The union of two volumes of carbon monoxide with one of oxygen may be shown by introducing a little 30 per cent. potash above the mercury in the eudiometer; while in a subsequent experiment (without potash) the volume of the carbon dioxide formed may be determined.

The formation of hydrochloric acid from one volume of hydrogen and one of chlorine may be shown with a fair degree of accuracy, if the mercury trough

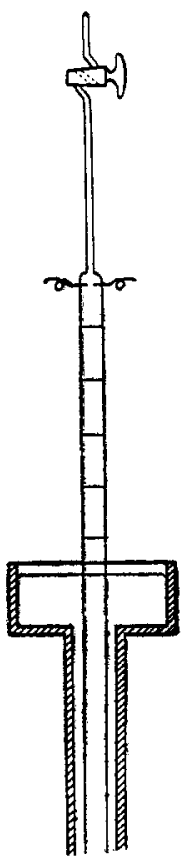

Fig.2. be replaced by brine from the chlorine gasometer in a tall glass cylinder.

In many cases, notably with $\mathrm{CO}$ and $\mathrm{O}_{2}$, the gases must be mixed by shakiñ the tube vertically before passing the spark, or no explosion will occur.

Deville's Tube (Fig. 3.).-A coil of platinum wire hung vertically in the neck of a fractionating flask and heated by electricity, is just as efficient as any other "white hot platinum tube" in bringing about the dissociation of water vapor. It works very much better than the noisy induction sparks commonly employed.

If concentrated ammonia ( $\mathrm{sp} . \mathrm{gr} .0 .880$ ) be warmed in the flask, the apparatus may be made use of to effect the decomposition of $\mathrm{NH}_{3}$ into $\mathrm{N}_{2}$ and $\mathrm{H}_{2}$.

V. SULPHURIC ACID AND SODIUM CHLORIDE.

I. Concentrated sulphuric acid is poured into its own volume 
of a saturated solution of common salt in a test-tube. The mixture may be cooled under the tap and shaken; but in general a

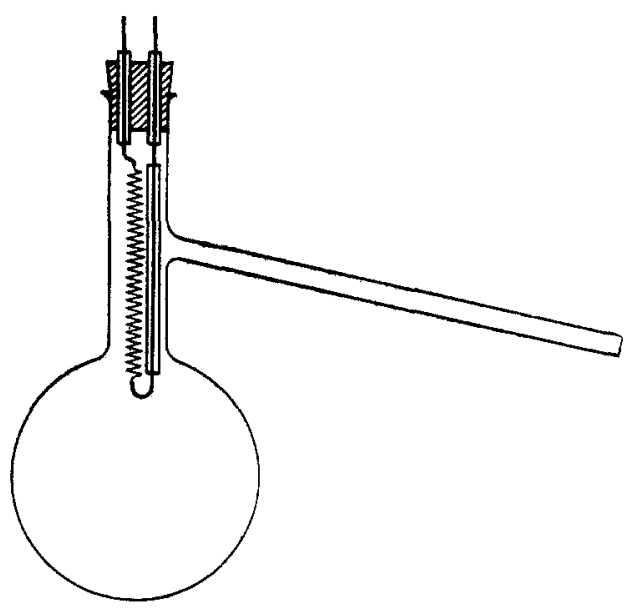

Fig.3.

crystal of Glauber's salt must be added before crystallization will occur. The liquid is poured off, and the crystals dried on a piece of unglazed porcelait.

2. If some of the sodium sulphate so prepared be covered with concentrated hydrochloric acid (on a watch-glass) it is at once changed to a fine powder of sodium chloride; which, in turn, may be freed from acid on a porous plate.

To demonstrate the change from chloride to sulphate, and back again, mix a drop of the original salt solution with a little water on a piece of glass the size of an ordinary lantern slide; warm till crystallization sets in, and throw the image on the screen (Fig. 4). The same may be done with small portions of the sulphate (Fig. 5) and sodium chloride formed in the experiment.

VI. ANTIMONY CHLORIDE AND HYDROGEN SULPHIDE.

An antimony solution is prepared as follows: Dissolve 2 grams tartar emetic in $5 \mathrm{cc}$. hydrochloric acid (sp. gr. I.I75); then 
add $85 \mathrm{cc}$. water. (This solution cannot be kept more than two or three bours as a precipitate of oxychloride is slowly formed.)

$$
{ }_{2} \mathrm{SbCl}_{3}+{ }_{3} \mathrm{H}_{2} \mathrm{~S} \rightleftarrows \mathrm{Sb}_{2} \mathrm{~S}_{3}+6 \mathrm{HCl} \text {. }
$$

(a) Pass a little $\mathrm{H}_{2} \mathrm{~S}$ into $5 \mathrm{cc}$. antimony solution.......

(b) Add $8 \mathrm{cc}$. hydrochloric acid (sp. gr. I.I75) $\ldots \ldots \ldots$

(c) " 5 " antimony solution $\ldots \ldots \ldots \ldots \ldots \ldots \ldots \ldots \ldots, \ldots$

(d) Heat, not to boiling......................

(e) Cool again (in a dish of water) $\ldots \ldots \ldots \ldots \ldots \ldots \ldots$,

(f) Add $6 \mathrm{cc}$. hydrochloric acid $\ldots \ldots \ldots \ldots \ldots \ldots \ldots \ldots$

(g) Pass in $\mathrm{H}_{2} \mathrm{~S}$ under pressure of 3 meters $\mathrm{Hg} \ldots \ldots \ldots \ldots$

(h) Reduce pressure by filter-pump $\ldots \ldots \ldots \ldots \ldots \ldots \ldots$

Notes.-(c) If the addition of antimony does not bring down

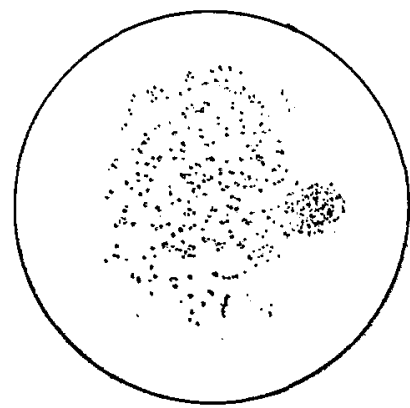

Fig. 4.

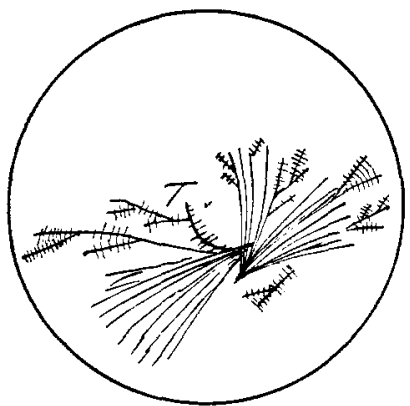

Fig. 5.

a fairly heavy precipitate, hydrogen sulphide should be passed in again, or there will be no precipitate in (e).

(e) Cool only until a precipitate appears, then add the acid $(f)$ and finishlcooling; if too much precipitate is formed it dissolves very slowly in the acid.

$(g)$ The"necessary pressure may be secured by means of the pump described below. With a rubber "syringe" (bulb and two valves) worked by hand, a pressure of about one meter of mercury (above the atmosphere) may be maintained; this is sufficient for the purposes of the experiment, but the precipitate comes much more slowly than when the pump is used. The object of the vacuum $(h)$ also is to save time.

The reaction may be conveniently carried out in the glass ves- 
sel represented in Fig. 6. The hydrogen sulphide enters by $A$ which may be tied in by wire round the ears $E . A$ is connected to the pump by rubber pressure tubing, and $B$ (the outlet) to

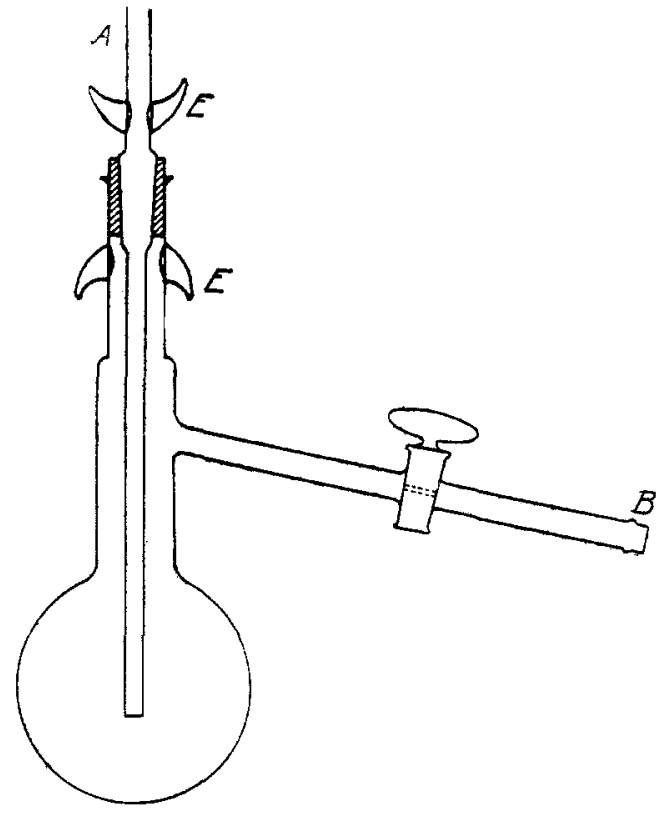

Fig. 6 .

the flue. All taps should be wired in. Joints may be made with ordinary rubber tubing covered with cloth and wired.

VII. PRESSURE PUMP FOR GASES.

The accompanying figure (Fig. $7^{1}$ ) represents the pump referred to in the preceding paragraphs. It consists of three pieces of black rubber tubing $T$ (of which two are shown in the figure) each I inch in diameter and 18 inches long, closed at the bottom and connected at the top by glass tubing to a pair of Bunsen valves. The valves are shown separately in Fig. 8 and are so arranged that on compressing the tubes the gas contained in

1 For the sake of clearness, the taps and handle which are actually behind the cylinder, are represented to one side of it. 
them is forced out through $D$, and on removing the pressure they are refilled through $F$.

The compression is effected by moving the handle $H$ to the position indicated in the figure, thereby opening the brass tap $W$ (communicating with the water mains) and closing $S$ (to the sink). Water thereupon flows through the glass pipe $P$ into the

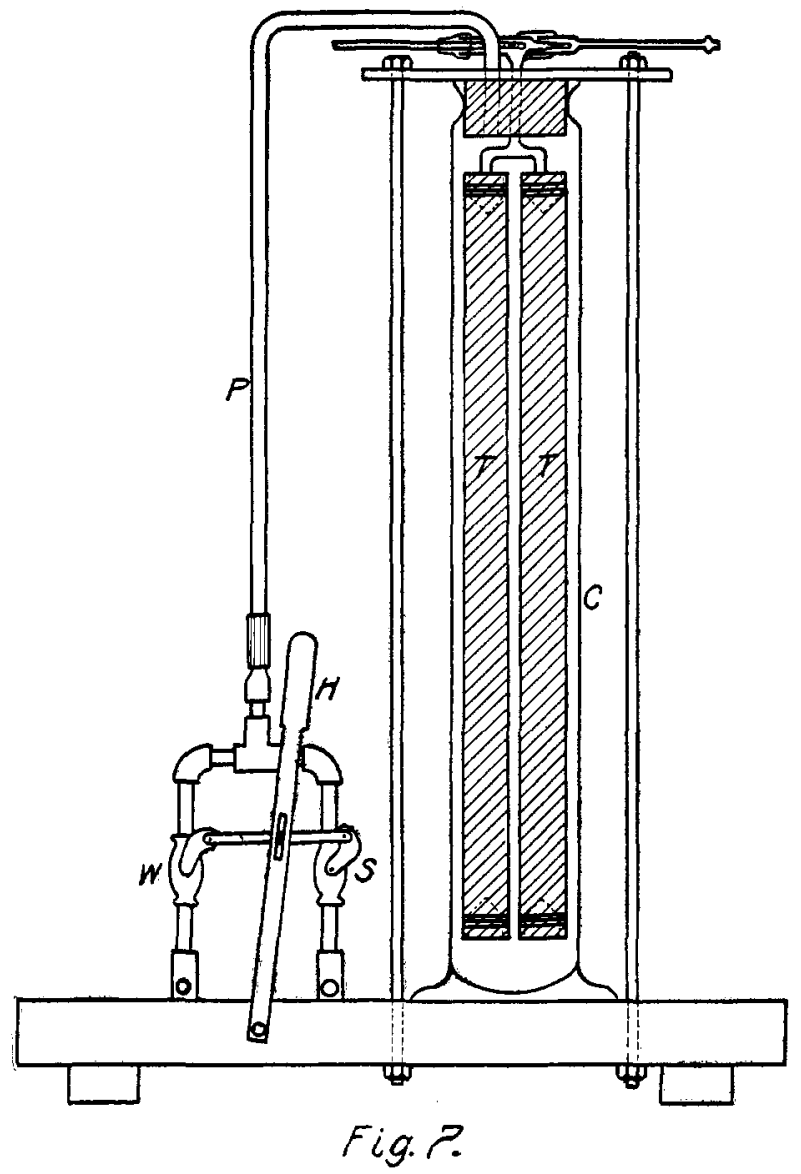

glass cylinder $C$ containing the rubber tubes $T$. Moving the handle in the opposite direction fills the tubes again with gas. The top of the cylinder is closed by a rubber plug covered with a brass plate ( $\frac{1}{4}$ inch thick) which is held down by four $\frac{1}{4}$-inch 
brass rods threaded at the ends and provided with nuts. The ends of the tubes are closed by glass plugs, wired in ; in order to keep the rubber from tearing, a wedge-shaped piece of cork is inserted at each end, as shown by the dotted lines in the figure.

The capacity of the pump is $500 \mathrm{cc}$. Three strokes are suffi-

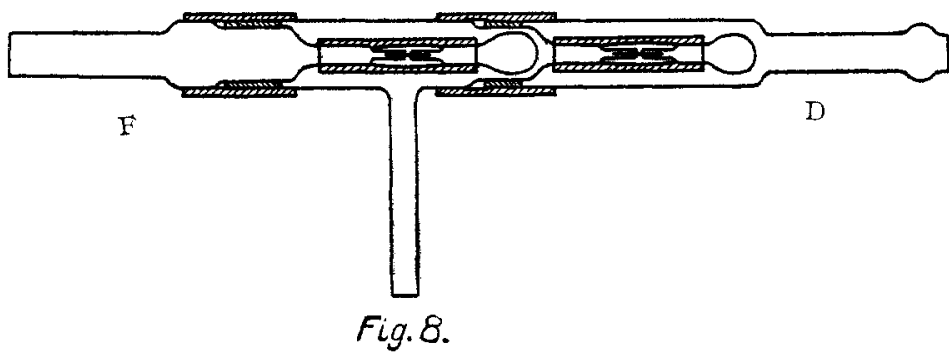

cient to attain the maximum pressure in the antimony sulphide experiment.

With this apparatus a gas can be brought to the pressure of the water system without coming into contact with any liquid. Higher pressure may be attained by using a force pump; the limit depends only on the strength of the apparatus and on the ratio between the variable volume (rubber tubing) and the constant volume (glass tubing) between the valves.

THE CHEMICAL LABORATORY OF THE CZNIVERSTIY OF TORONTO, April, IgOO.

[CONTRIBUTIONS FROM THE HAVEMEYER LABORATURIES OF COLCMBIA UNIVERSITY, No. 23.]

\section{A NEW ELECTROLYTIC CELL FOR RECTIFYING ALTERNATING CURRENTS.}

BI W. L, HILDBURGH.

Received Aprí 3, 1900.

I $\mathrm{N}$ electrical work an automatic device which will permit a current to pass through it in one direction only is frequently desirable, for rectifying alternating currents, for example, or for preventing a back-flow of current due to polarization. In addition to mechanical commutators several arrangements for the purpose have been previously known, but, with one exception, they are applicable to comparatively high voltages only. This exception is the two-cell rectifier described by Prof. M. I. Pupin 